\title{
A thin supported Pd-Au based membrane for hydrogen generation and purification: A case study
}

\author{
Adolfo Iulianelli $^{1 *}$, Yan Huang ${ }^{2}$, Angelo Basile ${ }^{1}$ \\ ${ }^{1}$ Institute on Membrane Technology of the Italian National Research Centre, Via P. Bucci Cubo 17/C c/o University of \\ Calabria, Rende (CS) 87036, Italy \\ ${ }^{2}$ Nanjing Tech University, Nanjing 210009, China
}

Corresponding Author Email: a.iulianelli@itm.cnr.it

https://doi.org/10.18280/mmep.050406

Received: 22 May 2018

Accepted: 1 December 2018

\section{Keywords:}

$\mathrm{Pd}$ and $\mathrm{Pd}-\mathrm{Au}_{\mathrm{A}} \mathrm{Al}_{2} \mathrm{O}_{3}$ membranes, hydrogen separation, $\mathrm{H}_{2} / \mathrm{N}_{2}$ selectivity, methane steam reforming

\begin{abstract}
In this work, a composite membrane based on a thin Pd-Au metallic layer supported on a ceramic substrate was produced by electroless plating deposition with the intent of generating and, meanwhile, purifying hydrogen in a single stage. Permeation tests were performed with pure gases $\left(\mathrm{H}_{2}, \mathrm{~N}_{2}, \mathrm{CO}_{2}, \mathrm{CH}_{4}\right)$ on both of them by varying the temperature between $300{ }^{\circ} \mathrm{C}$ and $400{ }^{\circ} \mathrm{C}$ and the feed pressure from 150 to $250 \mathrm{kPa}$ to evaluate the hydrogen perm-selectivity characteristics of the membrane.

A reference $\mathrm{H}_{2} / \mathrm{N}_{2}$ ideal selectivity around 500 was reached at $400{ }^{\circ} \mathrm{C}$ and $50 \mathrm{kPa}$ of transmembrane pressure and it remained stable up to $600 \mathrm{~h}$ under operation. The presence of defects on the metallic layer affected negatively the membrane performance in terms of $\mathrm{H}_{2}$ perm-selectivity, probably caused by the absence on an intermediate layer, which did not compensate the mechanical stress due to different thermal dilation coefficients within the metallic layer and the ceramic substrate.
\end{abstract}

\section{INTRODUCTION}

The growing attention towards the hydrogen utilization as energy carrier involved a high demand on hydrogen permeable membranes as compact devices for hydrogen separation and purification [1]. Several studies in the open literature demonstrated that composite Pd-based membranes are very effective for the aforementioned purposes, particularly if compared to the utilization of unsupported Pd-based membranes because of their high cost and mechanical limitations [2-3]. Palladium and its alloys possess a particular behavior to be fully hydrogen perm-selective over all of the other gases and this has been extensively studied in the last decades [4].

It is well known that hydrogen permeation through palladium-based membranes follows a solution/diffusion mechanism and many studies were conducted on selfsupported thick Pd-based membranes $(>5 \mu \mathrm{m}$ of dense palladium or palladium-alloy layer) because presenting full hydrogen perm-selectivity but low permeability as well as resulting extremely expensive as much as the membrane was thick [5]. In order to improve the hydrogen permeance, meanwhile reducing the amount of palladium utilized and, consequently, the membrane cost, in the last twenty years, much attention was paid for manufacturing thin palladium and palladium-alloy films supported on porous substrates (both ceramic and metallic) [6-10].

However, the hydrogen transport through a dense layer of palladium or palladium-alloy takes place under a driving force (from a high to a low pressure gas region) in a multi-step mechanism involving: (a) the diffusion of molecular hydrogen on the palladium membrane surface, (b) reversible dissociative adsorption on the palladium surface, (c) dissolution of atomic hydrogen into the metal bulk, (d) diffusion of atomic hydrogen through the bulk metal, (e) association of hydrogen atom on the palladium surface, (f) desorption of molecular hydrogen from the surface, $(\mathrm{g})$ diffusion of molecular hydrogen away from the surface [11].

Commonly, hydrogen permeation through a pd-based membrane is represented by the equation reported below (eq. 1):

$J_{H_{2}}=\frac{P\left(p_{h p s}^{n}-p_{l p s}^{n}\right)}{\delta}$

$\mathrm{J}_{\mathrm{H} 2}$ represents the hydrogen flux permeating through the dense layer of palladium or palladium-alloy, $\mathrm{P}$ is the hydrogen permeability, $\delta$ the thickness of the palladium/palladium alloy layer, $\mathrm{p}_{\mathrm{hps}}$ and $\mathrm{p}_{\mathrm{lps}}$ the hydrogen partial pressures on the high pressure (feed) and low pressure (permeate) sides, respectively, while " $n$ " is the pressure exponent. n-value can vary from 0.5 to 1 depending on the rate-determining step among the hydrogen permeation steps reported above. In case of bulk diffusion through the palladium layer controlling the hydrogen permeation mechanism, $\mathrm{n}$ is 0.5 (Eq. 1 becomes the SievertsFick) and, consequently, the Pd-based membrane shows fully hydrogen perm-selectivity. On the contrary, in case of mass transport to or from the surface, dissociative adsorption or associative desorption are the rate determining stage, $n$ is 1 since the processes depend linearly on the concentration of molecular hydrogen.

Among a number of supported palladium-alloy membranes, $\mathrm{Pd}-\mathrm{Au}$ composite membranes attracted a growing interest because gold ensures higher resistance to the catalytic poisoning and corrosive degradation acted by sulfur compounds, globally enhancing the hydrogen permeability over pure palladium (up to $15 \% \mathrm{Au}$ content) and reducing the 
embrittlement phenomenon [12-13]. In early studies, $\mathrm{Pd}-\mathrm{Au}$ membranes were prepared by expensive metallurgical processes with a thickness ranging from 25 to $100 \mu \mathrm{m}$ and using intermediate layers [14]. More recently, supported thin $\mathrm{Pd}-\mathrm{Au}$ alloy membranes were prepared by electroless plating or electroplating technique on different porous substrates, experimentally analyzing the hydrogen perm-selectivity performance and the chemical-physical resistance [15-19]. The intent of this work is to give an overview about Pd-based membranes, paying special attention to the preparation and characterization of composite Pd-alloyed membranes for hydrogen production (in membrane reactor modules), separation and purification.



Figure 1. Metallic layers electrodeposition steps for the Pd$\mathrm{Au} / \mathrm{Al}_{2} \mathrm{O}_{3}$ membrane, a) ceramic substrate; b) Pd deposition;

c) $\mathrm{Au}$ deposition; d) $\mathrm{Pd}-\mathrm{Au} / \mathrm{Al}_{2} \mathrm{O}_{3}$ final membrane

As a case study, a new generation of $\mathrm{Pd}-\mathrm{Au}$ membranes supported on a ceramic substrate (Figures 1,2) is studied considering the absence of an intermediate layer, by varying pressure and temperature, meanwhile evaluating their effects on n-value in the Sieverts' equation and the stability of the membrane in terms of $\mathrm{H}_{2} / \mathrm{N}_{2}$ reference selectivity and hydrogen permeating flux with respect to the thermal cycles.

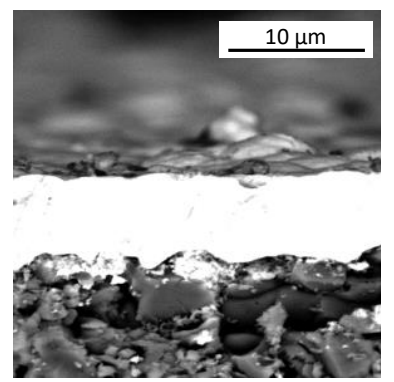

Figure 2. Cross section of the $\mathrm{Pd}-\mathrm{Au} / \mathrm{Al}_{2} \mathrm{O}_{3}$ membrane (Pd$\mathrm{Au}$ metallic layer is around $8 \mathrm{~mm}$ )

Furthermore, a comparison among our study and the $\mathrm{Pd} / \mathrm{Pd}$ alloyed membranes present in literature is also illustrated.

\section{EXPERIMENTAL}

The case study of this work considers a not commercial Pd$\mathrm{Au} / \alpha-\mathrm{Al}_{2} \mathrm{O}_{3}$ membrane showing an average metallic layer of $8 \mu \mathrm{m}$, total length of $7.5 \mathrm{~cm}$ (5.0 cm of active length), o.d. 13 $\mathrm{mm}$ and i.d. $8 \mathrm{~mm}$. Pd-Au layer was deposited via electroless plating technique following a multistage process. Indeed, when the $\mathrm{Pd}$ deposition was completed, the $\mathrm{Pd} / \mathrm{Al}_{2} \mathrm{O}_{3}$ sample was soaked with water before Au plating. The plating agent comprises $1 \mathrm{~g} / \mathrm{L} \mathrm{HAuCl}_{4} \cdot 4 \mathrm{H}_{2} \mathrm{O}, 70 \mathrm{~g} / \mathrm{L} \mathrm{Na} \mathrm{NaDTA}_{2}$ and 250 $\mathrm{mL} / \mathrm{L} \mathrm{NH} \cdot \mathrm{H}_{2} \mathrm{O}$, the reducing agent is a $0.5 \mathrm{~mol} / \mathrm{L} \mathrm{N}_{2} \mathrm{H}_{4}$ solution. The composite membrane was housed in the membrane module and two graphite gaskets were used to prevent the mixing within permeate and retentate streams. The operating temperature was varied between $300^{\circ} \mathrm{C}$ and $400{ }^{\circ} \mathrm{C}$, and feed pressure between $150 \mathrm{kPa}$ (abs.) and $250 \mathrm{kPa}$ (abs.), while the permeate pressure was kept constant at $100 \mathrm{kPa}$ (abs.) in the whole experimental campaign.

The ideal $\mathrm{H}_{2}$ perm-selectivities (Eq. 2) of the supported Pd$\mathrm{Au} / \alpha-\mathrm{Al}_{2} \mathrm{O}_{3}$ membrane were experimentally evaluated by permeation tests with pure $\mathrm{N}_{2}, \mathrm{H}_{2}, \mathrm{CH}_{4}$ and $\mathrm{CO}_{2}$. The volume flow rate of each pure gas permeating through the membrane was measured by means of a bubble-flow meter as an average value of at least 10 experimental points.

$$
\alpha_{\mathrm{H} 2 / \mathrm{i}}=\mathrm{J}_{\mathrm{H} 2} / \mathrm{J}_{\mathrm{i}} \quad\left(\mathrm{i}=\mathrm{N}_{2}, \mathrm{CO}_{2}, \mathrm{CH}_{4}\right)
$$

where, $\mathrm{J}_{\mathrm{H} 2}$ and $\mathrm{J}_{\mathrm{i}}$ are the $\mathrm{H}_{2}$ permeating flux (Eq. 1) and the permeating flux of another pure gas among $\mathrm{CO}_{2}, \mathrm{~N}_{2}$ and $\mathrm{CH}_{4}$.

A X-ray diffraction (XRD) analysis was carried out on a Siemens D8 Bruker-Axs III diffractometer with $\mathrm{Cu}-\mathrm{K}_{\alpha}$ radiation operating at $40 \mathrm{kV}$ and $30 \mathrm{~mA}$.

SEM analyses were done using a Phenom ProX desktop.

\section{DISCUSSION}

XRD patterns of Pd-Au membrane before and after heat treatment are illustrated in Figure 3. The higher intensity of $\mathrm{Au}$ signals is because the outer layer of the membrane precursor is $\mathrm{Au}$.

After heat treatment, both palladium and gold with a cubic crystallinity were completely transferred into Pd-Au alloy with a cubic crystallinity. As shown in Figure 3, the peak of the Pd$\mathrm{Au}$ alloy is closer to that of palladium, probably because of the much larger content of palladium.

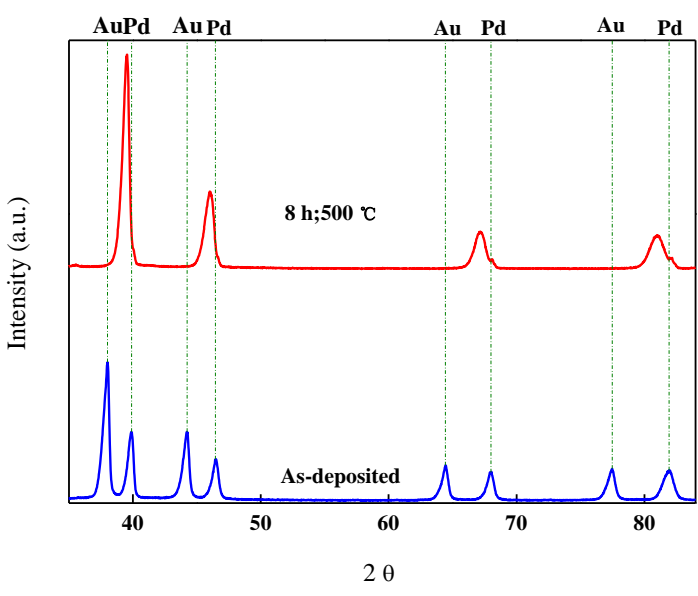

Figure 3. XRD Patterns of Pd-Au membrane

The $\mathrm{H}_{2}$ hydrogen flux permeating through the composite membrane at various temperatures and by varying the transmembrane pressure between 150 and $250 \mathrm{kPa}$ is reported in Figures 4-6, where the graphical assessment of "n-value" indicated that the best fitting is reached at $n=0.5$. 


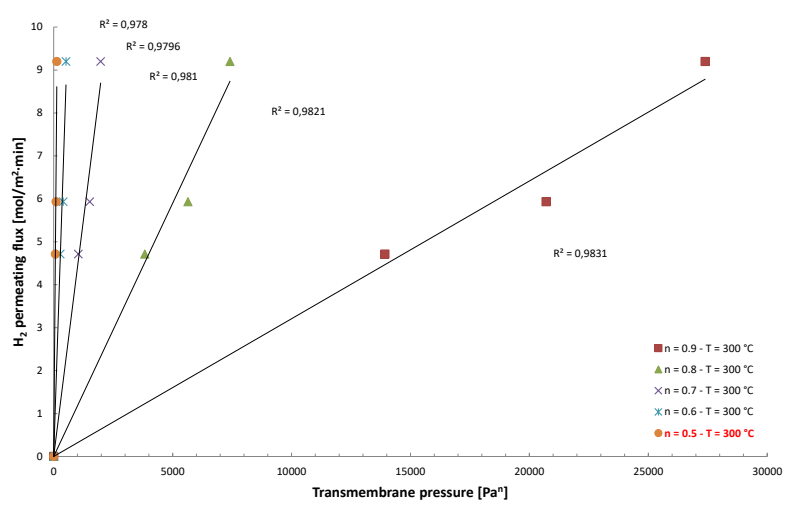

Figure 4. Graphical assessment of $\mathrm{H}_{2}$ permeating flux vs transmembrane pressure at $300{ }^{\circ} \mathrm{C}$ for the $\mathrm{Pd}-\mathrm{Au} / \mathrm{a}-\mathrm{Al}_{2} \mathrm{O}_{3}$ membrane

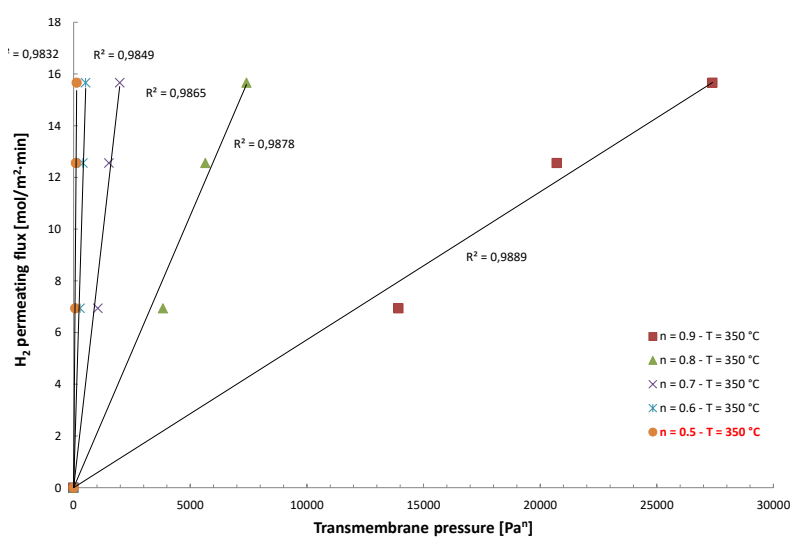

Figure 5. Graphical assessment of $\mathrm{H}_{2}$ permeating flux vs transmembrane pressure at $350{ }^{\circ} \mathrm{C}$ for the $\mathrm{Pd}-\mathrm{Au} / \mathrm{a}-\mathrm{Al}_{2} \mathrm{O}_{3}$ membrane

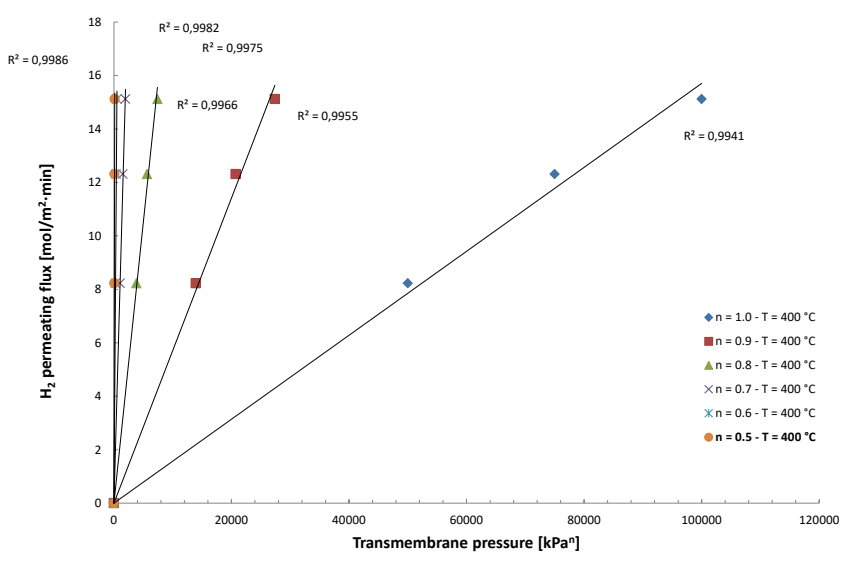

Figure 6. Graphical assessment of $\mathrm{H}_{2}$ permeating flux vs transmembrane pressure at $400{ }^{\circ} \mathrm{C}$ for the $\mathrm{Pd}-\mathrm{Au} / \mathrm{a}-\mathrm{Al}_{2} \mathrm{O}_{3}$ membrane

Consequently, being $\mathrm{n}=0.5$ for all the temperatures investigated in this work, the mechanism regulating the $\mathrm{H}_{2}$ transport through the $\mathrm{Pd}-\mathrm{Au} / \mathrm{Al}_{2} \mathrm{O}_{3}$ membrane can be described by the Fick-Sieverts law (Eq. 3).

$J_{H_{2}}=\frac{P\left(p_{h p s}^{0.5}-p_{l p s}^{0.5}\right)}{\delta}$

The resulting $\mathrm{H}_{2} /$ other gas selectivities are then reported in Table 1 (at $400{ }^{\circ} \mathrm{C}$ ).
Table 1. Perm-selectivity characteristics of the $\mathrm{Pd}-\mathrm{Au} / \mathrm{Al}_{2} \mathrm{O}_{3}$ membrane at $400{ }^{\circ} \mathrm{C}$

\begin{tabular}{ccccc}
\hline \multicolumn{5}{c}{ Ideal selectivity $-\mathbf{T}=\mathbf{4 0 0}{ }^{\circ} \mathrm{C}$} \\
\hline $\mathrm{J}_{\mathrm{H} 2}\left[\mathrm{~mol} / \mathrm{m}^{\mathbf{2}} \cdot \mathrm{min}\right]$ & $\Delta \mathrm{p}[\mathrm{kPa}$ & $\boldsymbol{\alpha}_{\mathrm{H} 2 / \mathrm{N} 2}$ & $\boldsymbol{\alpha}_{\mathrm{H} 2 / \mathrm{CO}}$ & $\boldsymbol{\alpha}_{\mathrm{H} 2 / \mathrm{CH} 4}$ \\
\hline 8.2 & 50 & 500 & $\sim 630$ & 350 \\
\hline
\end{tabular}

As stated above, the hydrogen transport mechanism through the membrane is the Fick-Sieverts law and, consequently, higher $\mathrm{H}_{2}$ perm-selectivities were expected. However, the low $\mathrm{H}_{2}$ perm-selectivity values reported in Table 1 can be justified by the possible presence of defects in the separative metallic layer, which favored the transport of other gases besides hydrogen with a different mechanism from diffusion. The defects in the metallic film could be related to the absence of an intermediate layer, responsible of a not uniform metallic thickness distribution on the porous ceramic support. Indeed, this probably made possible local imperfections in the $\mathrm{Pd}-\mathrm{Au}$ film. It was also reflected in the decreasing trend of the permselectivities at higher transmembrane pressures, which favored higher pure gas flow rates in the defects of the metallic layer.

Generally speaking, an intermediate layer plays a crucial role when $\mathrm{H}_{2}$ selective metallic films are deposited on porous metallic supports. Indeed, it acts as a barrier limiting the intermetallic diffusion. On the contrary, for porous ceramic supports, in which its roughness should favor a better adhesion of the deposited metallic layer, the intermediate layer is useful to compensating the effect of the thermal dilatation of the two different materials constituting the composite membrane, avoiding the formation of defects and, consequently, the membrane failure.

The negative role of the absence of the intermediate layer was checked by analyzing the effects of the thermal cycles on the perm-selectivity performance of the composite membrane. After almost $650 \mathrm{~h}$ under operation, the membrane module was cooled down at room temperature and heated up once again at $400{ }^{\circ} \mathrm{C}$ to observe the effect of the thermal cycle. At this temperature and $\Delta \mathrm{p}=50 \mathrm{kPa}$, a dramatic decrease of $\mathrm{H}_{2} / \mathrm{N}_{2}$ ideal selectivity was observed, inducing to stop the experimental tests and confirming that the different thermal dilation/contraction coefficients the of $\mathrm{Pd}-\mathrm{Au}$ layer and ceramic support were responsible of local cracks in th separative layer, consequently making possible low $\mathrm{H}_{2}$ permselectivity values.

\section{CONCLUSIONS}

$\mathrm{A} \mathrm{H}_{2} / \mathrm{N}_{2}$ ideal selectivity around 500 was reached at $400{ }^{\circ} \mathrm{C}$ and $50 \mathrm{kPa}$ of transmembrane pressure and it remained stable up to $600 \mathrm{~h}$ under operation. The presence of defects on the metallic layer affected the $\mathrm{H}_{2}$ perm-selectivity of the membrane and it was probably caused by the absence of an intermediate layer, useful for compensating the mechanical stress due to different thermal dilation coefficients of the two materials constituting the composite membrane.

\section{REFERENCES}

[1] Alavi M, Iulianelli A, Rahimpour MR, Eslamloueyan R, De Falco M, Bagnato G. (2017). Basile fixed bed membrane reactors for ultrapure hydrogen production: 
Modelling approach. Hydrogen Production, Separation and Purification for Energy, Institution Engineering and Technology 231-257.

[2] Iulianelli A, Basile A. (2018). Advances on inorganic membrane reactors for production of hydrogen. Encyclopedia of Sustainability Science and Technology 1-11. https://doi.org/10.1007/978-1-4939-2493-6_948-1

[3] Basile A, Iulianelli A, Tong J. (2015). Single-stage hydrogen production and separation from fossil fuels using micro- and macromembrane reactors. Compendium of Hydrogen Energy 1: 445-468. http://dx.doi.org/10.1016/B978-1-78242-361-4.00015-7

[4] Zornoza B, Casado C, Navajas A. (2015). Advances in hydrogen separation and purification with membrane technology. Palladium membrane technology for hydrogen production, carbon capture and other applications: Principles, energy production and other applications. Woodhead Publishing Series in Energy 167-191.

[5] Paglieri S, Way J. (2002). Innovations in palladium membrane research. Separation and Purification Methods 31(1): 1-169. http://dx.doi.org/10.1081/SPM120006115

[6] Zhang X, Xiong G, Yang W. (2008). A modified electroless plating technique for thin dense palladium composite membranes with enhanced stability. Journal of Membrane Science 314(1): 67-84 http://dx.doi.org/10.1016/j.memsci.2008.01.051

[7] Jun CS, Lee KH. (2000). Palladium and palladium alloy composite membranes prepared by metal-organic chemical vapor deposition method (cold-wall). Journal of Membrane Science 176(1): 121-130. http://dx.doi.org/10.1016/S0376-7388(00)00438-5

[8] Li H, Caravella A, Xu HY. (2016). Recent progress in Pd-based composite membranes. Journal of Materials $\begin{array}{llll}\text { Chemistry } & \text { A } & \text { 4(37): } & \text { 14069-14094. }\end{array}$ http://dx.doi.org/10.1039/C6TA05380G

[9] Ma YH, Mardilovich IP, Engwall EE. (2003). Thin composite palladium and palladium/alloy membranes for hydrogen separation. Annals of the New York Academy of $\quad$ Sciences 984(1): 346-360. http://dx.doi.org/10.1111/j.1749-6632.2003.tb06011.x

[10] Yun S, Ted Oyama S. (2011). Correlations in palladium membranes for hydrogen separation: A review. Journal of Membrane Science 375(1-2): 28-45. http://dx.doi.org/10.1016/j.memsci.2011.03.057

[11] Basile A, Blasi A, Fiorenza G, Iulianelli A, Longo T, Calabrò V. (2011). Membrane and membrane reactor technologies in the treatment of syngas streams produced from gasification processes. in Gasification: Chemistry, Processes and Applications, Michael D. Baker (Ed.), Nova Sci. Pub. 139-174.

[12] Shi L, Goldbach A, Zeng G, Xu H. (2010). Preparation and performance of thin layer $\mathrm{PdAu} / \mathrm{ceramic}$ composite membranes. International Journal of Hydrogen Energy 35(9):

http://dx.doi.org/10.1016/j.ijhydene.2010.02.048

[13] Way JD, Lusk M, Thoen P. (2008). Sulfur-resistant composite metal membranes. US Patent 2008/0038567, Feb. $\quad 14,2008$. https://techportal.eere.energy.gov/application.do/ID $=21$ 924

[14] Gade SK, Payzant EA, Park HJ, Thoen PM, Way JD. (2009). The effects of fabrication and annealing on the structure and hydrogen permeation of $\mathrm{Pd}-\mathrm{Au}$ binary alloy membranes. Journal of Membrane Science 340(12): http://dx.doi.org/10.1016/j.memsci.2009.05.034

[15] Chen CH, Ma YH. (2010). The effect of H2S on the performance of $\mathrm{Pd}$ and $\mathrm{Pd} / \mathrm{Au}$ composite membrane. Journal of Membrane Science 362(1): 535-544. http://dx.doi.org/10.1016/j.memsci.2010.07.002

[16] Iulianelli A, Alavi M, Bagnato G, Liguori S, Wilcox J, Rahimpour MR, Eslamlouyan R, Anzelmo B, Basile A. (2016). Supported Pd-Au membrane reactor for hydrogen production: Membrane preparation, characterization and testing. Molecules 21(5): 581-594. https://doi.org/10.3390/molecules21050581

[17] Tardini A, Gerboni C, Cornaglia L. (2013). PdAu membranes supported on top of vacuum-assisted $\mathrm{ZrO}_{2}$ modified porous stainless steel substrates. Journal of Membrane Science 428: 1-10. http://dx.doi.org/10.1016/j.memsci.2012.10.029

[18] Lee SW, Oh DK, Park JW, Lee CB, Lee DW, Park JS, Kim SH, Hwang KR. (2015). Effect of a Pt- $\mathrm{ZrO}_{2}$ protection layer on the performance and morphology of $\mathrm{Pd}-\mathrm{Au}$ alloy membrane during H2S exposure. Journal of Alloys and Compounds 641: 210-215. http://dx.doi.org/10.1016/j.jallcom.2015.03.210

[19] Patki NS, Lundin ST, Way JD. (2018). Apparent activation energy for hydrogen permeation and its relation to the composition of homogeneous PdAu alloy thin-film membranes. Separation and Purification Technology 191: 370-374. http://dx.doi.org/10.1016/j.seppur.2017.09.047 